INTERVIEW

\title{
MAREK SKYSL'AK: LEARN IN EVERY SINGLE MOMENT OF YOUR LIFE
}

\author{
Marek Skysl'ak is the Country Manager of Procter \& Gamble for the Czech and Slovak Republics. \\ He talks, in his exclusive interview for CEBR, about corporate culture, marketing, career development \\ and other interesting topics.
}

It's often said that only the most ambitious Slovaks come to work in the Czech Republic. What do you think about that? And do you see any difference between Czechs and Slovaks?

I can see some differences but they're not dramatic. With Czechs, I notice they like travelling more and have an adventurous spirit. Whenever I travel in Slovakia or even around the world, I meet many Czechs. It's also noticeable when it comes to sporting activities, for example cycling. Almost every Czech is into cycling and there are cycling paths everywhere; you don't see that in Slovakia. But I can't say that Czechs and Slovaks react differently in particular situations, nor I can say that they're better or worse people; I can't see that significant of differences.

Many people think of moving to the west as some sort of career advancement. Slovaks move to the Czech Republic, Czechs to Germany and Germans to England. Do you think that the fact that you are now working in Prague was an important change in your career?

I wouldn't call moving to the west an advancement in one's career. There are trends of moving to the west but that's more connected with the size of the business and amount of opportunities in given areas. And Prague can be considered a center of business. If you're saying that Czechs are moving to Germany, there might be something about it but I tend to think that people simply look for an environment that fits them better from the cultural point of view. And if they're offered a working opportunity, they move.
Let's stay on the topic of comparing a bit longer and focus on management; this is the topic we are very often dealing with. Do you think that Central European managers are specific in some way? Could you say they're better or worse at something when compared to managers from the West?

If I should relate my answer to our firm, I couldn't say anything like that. We're a global company with a unified corporate culture that's practically identical in all countries. People from various countries have to make decisions about very similar things and I can't say that people from particular countries are more creative or better in any way than people from other countries. I wouldn't generalize this, if someone does better than others, it's more about specific personal abilities.

In our company, we use a principle which we call "Build from within". That means that our employees start their career at a basic position and then try to evolve and get promoted. They learn from their superiors and live in our unified corporate culture right from the start. That's why I can't see any differences between our employees from different countries when travelling. Our unified corporate culture works as a common language.

Corporate culture is becoming a more and more frequently discussed topic. It is something that has to come from the top management. What do you, as a head of an international organization, think is the best way to make the corporate culture work well? 
I think it's a long-term process, something that can't be changed from day to day. Our company celebrates its $175^{\text {th }}$ anniversary this year. The basic principle of our corporate culture is PVP, which stands for purpose, values and principles. Right after recruitment, we observe how people fit into this scheme. Our employee evaluation and all of the trainings are aimed at this principle. Therefore, PVP is integrated into everyday life in our company; it's not a forced process. But the already mentioned consistency and longevity of our firm play a very important role as well. Obviously, some minor aspects of our corporate culture are innovated but there are no rapid changes.

It's very often said: "Our employees are the most important." But how do you make sure that they feel this way, too? How do you make them identify with corporate culture and its basic values? Is it the question of consistency as well?

That's a very difficult question. If I should speak about our company, I'd say that one of our crucial values is integrity. We try to make the companies and their people connected. I believe that if this works, people are motivated, they wish to educate themselves and that guarantees the good results of the whole company. What also helps us is the aforementioned "Build from within" principle. We don't accept people from outside our firm to higher positions. Everyone starts from scratch, has to go through the whole system and learn. So, after all those years, they understand the principles of the corporate culture perfectly and know how to apply and pass them on. Also, as people get promoted, they need their subordinates to evolve. If they wish to move on, they have to find someone to replace them and also keep a stable group of subordinate employees.

Don't you recruit any managers from outside your firm at all? Do you really bring up all the employees for leading positions on your own?

Yes. This can happen only if we buy some company and its employees make it into higher positions after some time but other than that, we really bring up all of our employees.

How do you avoid alienation in a structure this complicated? How do you introduce humanity into such a difficult process and how do you make sure that people work because they like it and not only because they're told to by the firm?

Apart from the already mentioned system, we also use evaluating and control mechanisms from which we obtain feedback from the organization. Also, we organize a so-called "Organization Survey" by which we investigate employees' perception of our corporate culture and then we try to fix the elements that don't work.
Czech and Slovak Republic may be right in the heart of Europe but generally, they are not considered the most important. It is important to adapt to their specifics, though. Is there any space for adaptation to different environments in terms of your unified corporate culture?

I'll try to answer your question by an example of how we dealt with the given issue a year or two ago. Of course, we have a corporate strategy which cannot be changed but we understand that the consumer can be different in different countries. And we try to adapt to this. There are regions that are in competence of one management. Let's take the region of Central Europe. In the past, we had two regions: Central Europe - south and Central Europe - North. South were the Czech Republic, Slovakia, Hungary, Slovenia and Croatia and north were Poland and Baltic countries. At some time, we analyzed the needs of consumers in given regions and the way they perceive us. We found out that the consumer in this region is relatively similar and based on that, we decided to change the structure and united these two clusters under one management. A bigger region is more significant. The aim was, to set the best communication and come up with the best innovations that respect the wishes of the consumer from the given region. The whole organizational structure and management had been changed and we believe that it will help us to aim better at the consumer from this region.

\section{Marketing is often perceived as making commer-} cials. That certainly is important, but it's actually the last step, marketing itself is about something else. What is the position of marketing in your firm? How do you perceive it?

I perceive marketing as something that focuses on the consumer. That consumer has needs, based on which he chooses what he wants. If a company wishes to apply a marketing approach, it has to recognize those needs and, according to them, offer the right products and get them to the consumers. Marketing approach is not about advertising. It usually starts with research and development. That means recognition of current trends and consumer's needs. Then the brand development comes: once we know what the customer demands, it is necessary to find out what to give to him and whether it's a service or a product. After we have that product or service, we need to create a bond with the consumer, and that's where the communication begins - perhaps in the form of advertising. This is marketing as I perceive it.

But this is only a part of the overall approach. We have to get the product to the consumer, so the entire supply chain is important. We need to know how to bring him the product, in which place and in what form. When the product is at 
its place, we need to know how to provide support for it. So, there's lot of important elements and when one of those things doesn't work, the whole system won't meet our expectations or we'll lose an opportunity. So, I perceive marketing as this entire complex of various elements.

According to our survey on the state of marketing in the Czech Republic, sales departments lead 55\% of companies, $22 \%$ of companies are maintained by financial department and only $12 \%$ of companies are led by marketing departments. How do you call the person who is in charge of marketing and all its elements in the company, then? And what is this person's position?

This depends on whether the company applies a marketing approach or a different one. The CEO is in charge of marketing as he has teams of people to help him lead the whole complex. We are a global company, so all the elements in our firm are global, not local. For example, research and development is done centrally for the whole company, not separately for each region. But the CEO puts the whole thing together. So it depends on whether the firm is organized locally or centrally, and who controls the individual components, but in general, dealing with marketing is a task for CEOs.

\section{Do you think that managers should give lectures to students and pass their experience on?}

Yes, I think so. There is a certain moment in everybody's life when one should start giving back what society has given him. He should pass the knowledge on and inspire people. At the end of the day, everyone will benefit from that. It's a part of the social cycle and I think it's good when this happens.

What do you think about today's graduates? What are their major flaws? Is it a lack of insight into practice or is it something else? And what are they good at?

I'd prefer to begin with the positive aspects. I think that the young people put much more effort into learning new things nowadays, and not only because of their careers. They want to know how to deal with life, too. That is a very positive thing.

And what is missing? Sometimes young people don't realize the importance of education. They often go to school only to pass it and have a degree, but they forget that the school should also give them something. It should help them with self-development; it should teach them how to react to different situations in life.

In order to learn and develop themselves, they need some inspiration, too. In our company, we maintain contact with universities; we try to organize case studies to show students

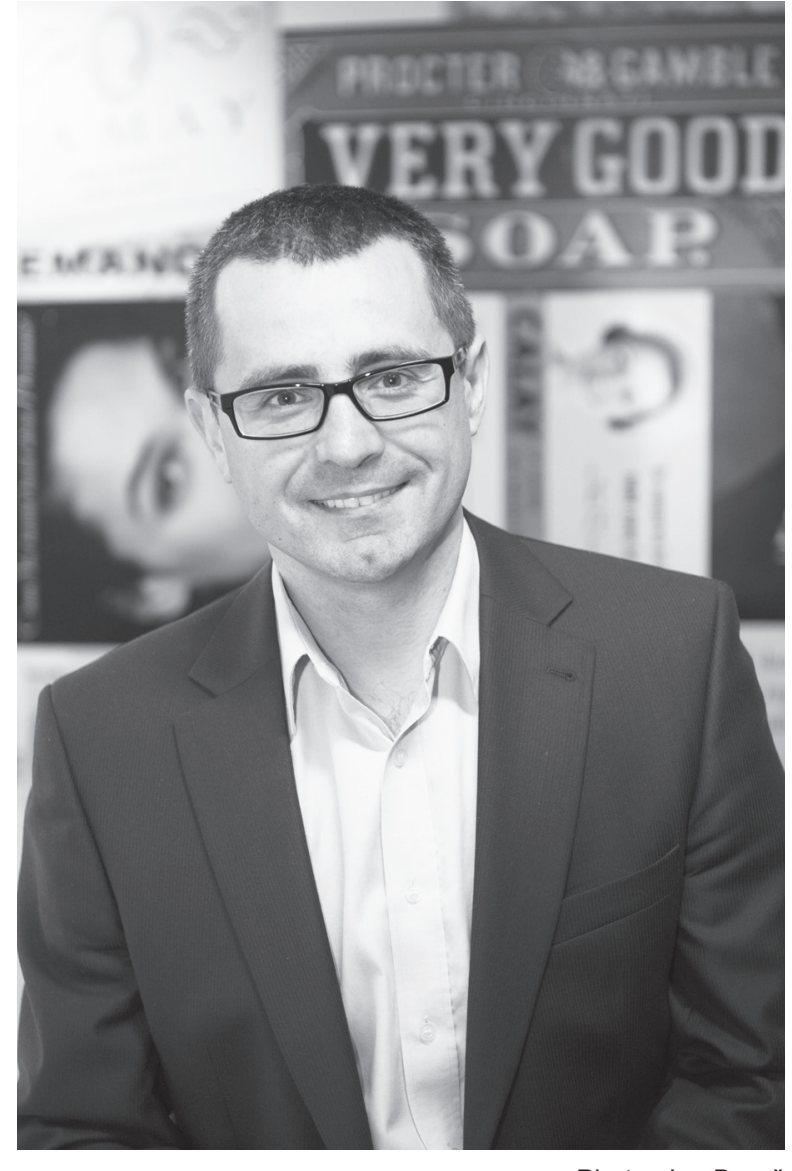

Photo: Jan Branč

how things actually work in business. So we try to contribute in inspiring the students.

\section{Should students work during their studies or should they fully focus on school?}

It's hard to say as this can be very individual. For example, some students have to pay for their studies, and it is an economic necessity for them to work, while others want to gain some experience and working habits. In that respect, it's really individual and I can't tell you which way is better. From my own experience I know that it's good to learn in every single moment of your life and it's even better if the learning process is supported by work.

On the other hand, if students don't have practical experience, it may be much harder for them to find a job, since many companies require at least some sort of experience. What is the situation in your company?

We don't require practical experience. We look for people with ability to achieve the best results in a challenging environment. But even though we don't require practice, people 
usually have it. It's either practice itself or it's an extracurricular activity, where people develop, learn, and where they can show their skills and abilities. If someone believes that the studies provide sufficient training and sufficient challenges, he's usually wrong.

What do you think that people will say about 2012 in fifty years, in 2062?

I think that people will hardly remember our time. They will perceive it as a distant history, the same as we perceive times 300 years ago from our point of view. The speed of developing new technologies is amazing, everything accelerates and digitizes, we connect the real and virtual world, and it will change people's minds, their needs and priorities and the pace of changes will become even faster. We are entering a world of uncertainty, instability and high complexity, so I think that in 50 years from now, our time will resemble ancient history. No one will know what happened back then, and the world will be completely different.

\section{What is the thing that fascinates you most in business or in personal life?}

Even though I don't understand them, I'm fascinated by current technologies and the pace of changes. I think it's one of the driving forces of our society. One or two years back, I thought that the phone is used only for making phone calls. But once I'd seen what my little children can do with today's phones, I realized that those devices aren't phones anymore. Making a phone call is the very last thing you can do with them. So I forced myself to buy a smartphone to keep up a bit, or soon I would be like a dinosaur, soon to become extinct. My little children, who are five or six years old, take the phone and they immediately know what to do with it and they always show me new things. For me, it's something completely strange and my brain is no longer capable of full comprehension. I can adapt to it, but I'll never fully understand it.

So, this is the area of the current trends. As for other things, I try to find something to relax, such as cooking and especially spending as much time with my family as I can.

Do you have any hobbies or do you do practice any sport?
I used to be a very active athlete, but lately I don't have much time for it. When I was younger I used to play football, which is the sport closest to my heart, but as I said, I don't have time for it now. I at least try to keep myself in shape by jogging or swimming occasionally.

Your family is Slovak, so you certainly spend a lot of time traveling in the car or on the train, don't you?

That is true. The train is better for me because you can rest a bit...

\section{So, you can play with your smartphone to catch up with your children.}

That wouldn't help. I may learn something, but I'd never catch up with them. They were born in the environment full of technology while we were born in a completely different environment, so we aren't capable of full adaptation. We can try, but children are in their element when it comes to modern technology.

\section{If you were not doing what are you doing now, what would you do? Would you be a football player?}

Probably not. The idea of playing football for a living is very nice because I really enjoy it, but it's not what I want. I am lucky to have a job that I enjoy. When I work on various assignments, I like every new assignment more than the previous one, so in this respect, I'm satisfied. But if I was just starting my career and I really had to choose, I'd probably want to become a chef. Or something related to traveling, because I like to travel. Those two things could be connected. A sommelier, some work in the field of tourism, gastronomy... something like that, I guess.

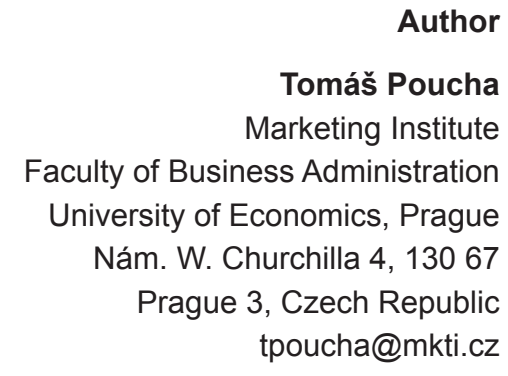

Author

Tomáš Poucha

aculty of Business Administration niversity of Economics, Prague ám. W. Churchilla 4, 13067

tpoucha@mkti.cz 